\title{
Offshore Software Development Outsourcing Contract from Vendors' Perspective: A Systematic Literature Review Protocol
}

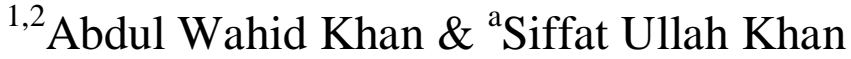 \\ ${ }^{I}$ Software Engineering Research Group (SERG_UOM), Department of Computer Science \& IT, University of \\ ${ }^{2}$ Malakand, Khyber Pakhtunkhwa, Pakistan. Institute of Engineering \& Computer Science (IECS), University of \\ Science \& Technology Bannu, Khyber Pakhtunkhwa, Pakistan
}

\begin{abstract}
Context - Offshore software development outsourcing (OSDO) is a modern business strategy for developing high quality software at low-wage countries at reduced cost. Outsourcing is a contract based association between vendor and client organization, where a client organization contracts-out with vendor organization for software development work to be provided by vendor organization in return for remuneration. Appropriate management of the OSDO contract plays an important role in the success of outsourced projects.

Objective - The objective of this protocol is to identify different critical success factors (CSFs) and critical barriers (CBs) that are considered critical for successful management and execution of the outsourcing contract in different stages of the contract i.e. pre-contract, during the contract and post-contract.

Method - Systematic Literature Review (SLR) will be used for the identification of the aforementioned factors. SLR is based on a structured protocol, and is therefore, different from ordinary review. SLR give more prescribed and less biased result from the ordinary literature review.

Expected Outcome - We have developed the SLR protocol and are currently in process of its implementation. The expected outcomes of this review will be the identification of critical success factors (CSFs) and critical barriers $(C B S)$ to be addressed by vendor organizations for appropriate management of OSDO contract. The ultimate outcome of the research is to develop Outsourcing Contract Management Model (OCMM).
\end{abstract}

Keywords - Systematic Literature Review, Outsourcing Contract Management, Software Development Outsourcing; Client-Vendor Relationships

\section{Introduction:}

"Software development outsourcing, or software outsourcing, is modern software engineering paradigm in the context of global software development, aiming at developing high-quality software in low wage countries at reduced cost" $[1,2]$. Software development outsourcing is a contract-based relationship between client and vendor organisations in which a client contracts out all or part of its software development activities to one or more vendor, who provide agreed services in return for remuneration [3, 4]. "Outsourcing is derived from finding the source from the outer", which is a kind of new service mode that the hosts deliver all or part of their IT business to other professional(service providers) SPs"[5].

Software outsourcing has been growing rapidly and it gave a new projection to business process [6]. A revolution of global software initiated in 1990 and proceeds towards success [7]. Forrester Research 2002 predicated that 3.3 million US professional jobs having worth of $\$ 136$ billion will be outsourced offshore by 2015 [8]. Most of the firms at USA and UK have adopted offshore software development outsourcing paradigm due to the availability of high quality of IT services at low cost and shorter period of time [9]. Majority of the offshore outsourcing vendor firms are in India, Ireland, China and Russia, whereas the client firms are in United States, United Kingdom and Japan [10]. Currently India is leading outsourcing industry whereas China is the strongest competitor to India [11, 12].

A good outsourcing contract not only encourage vendor and client organisations to get their desired goal but also motivate them to handle many practical issues that may cause the failure of the outsourcing contract [13]. Matthew K.O. Lee divide the outsourcing contract into pre-contract and post-contract for the best management of contract implementation [13]. Contract management has two major parts "control and flexibility" [14] and require more extension, whereas the managerial interest can get the trust of client, which will improve the contract relationship [15]. Developing an outsourcing contract for IS/IT area, the organisation should focus on internal organisation stability and contract flexibility [16].

The main objective of this research is to learn in-depth and understand the outsourcing contract management in the context of OSDO relationships from vendor's perspective. The expected outcome of the protocol is to identify the critical success factors (CSFs) and critical barriers (CBs) through systematic literature review (SLR) by vendor organizations to enhance the outsourcing contract management in OSDO relationships. 
Offshore software development outsourcing contract from vendors' perspective: a systematic

The ultimate goal of the research is to develop OCMM and the structured plan for the model to be developed has already been accepted for international conference Profes 2012, Madrid Spain.

\section{Background:}

The first outsourcing agreement was held in 1963 when Electronic Data Systems was hired for performing the data processing tasks for Blue Cross of Pennsylvania [17]. Kodak in 1998 [18] announced an information technology (IT) outsourcing agreement with International Business Machines (IBM), Business land, and Digital Equipment Corporation (DEC). Annual growing rate of outsourcing is 30\% [19]. The expected growth of IT goods and services of India is $10 \$$ billion in 2003 to $50 \$$ billion by 2008 [20, 21]. Main focus of the research study has been on "outsourcing determinants, benefits, vendor selection and contracting" [22].

A number of researchers have tried in the past research to identify the different issues regarding to the contract management between vendor and client. Different solutions have been proposed for relation improvement in context of the contract management between vendor and client organizations, for successful completion the outsourcing contract. The successful contract between the vendor and client organization can be achieved through constant communication for the purpose to find the problems, distance reduction and culture variation overcome. Kern.T [23] define the success points of client-vendor relationship to handle the conflict. Lacity et al, [18] have defined three types of contract on the basis of client-vendor relationship (Fee-for-service, Strategic alliance/partnership and Buy-in contract.). Expectation increase the trust between vendor and client and the contract is the baseline for the expectation. The proposed model of Kern et al, [22] fail to locate the actual processes required to maintain and enhance an outsourcing relationship. DiRomualdo et al, [24] stated "that the contract and the relationship are separate activities and should be developed and managed to be in line with strategic objectives of the organizations involved in the outsourcing agreement"

To increase the performance of IT outsourcing many organization shares numerous dedications, however outsourcing contract is the static hurdle and it is still immature. There is almost lack of reliable con tract in outsourcing among client and vendor. Huai. J [25] paper contributes techniques for the developing IT outsourcing contracts and has given the concept of Quality Function Deployment (QFD), which is introduced as a framework for managing IT outsourcing requirements. In manufacturing sector, the function of the QFD is properly applied to find client requirements at the initial stage of the development. The study finds the qualities of QFD system and the problem arise in the application of QFD in IT outsourcing contracts. The QFD properly locate the outsourcing client requirements and contributes to the outsourcing performance. The QFD methodology useful for finding the illustrated requirement of client-vendor outsourcing contract. Huai. J [25] defined the use of QFD methodology in IT outsourcing contracts and find the contract terms. Barthelemy.J [26] define different characteristic of the high-quality IT outsourcing contracts, i.e. (1) Preciseness, (2) Completeness, which reduce the potential opportunism of the vendor and less chance for costly renegotiations [27], (3) Balance, one side contract create a problem for any party. Vendor will try to get some revenue so impose extra fees [28]. The outsourcing contract having many advantages and various problems [29, 30].

The software outsourcing is growing rapidly and the firms can get significant operation saving, new technology adoption and decision making in strategic way. The success is not the guaranty, as half of the outsourcing projects failed in 2003 [31]. The survey indicates that 20\% of IT outsourcing relationship fail in the first two years, and 50\% within five years [32]. Outsourcing success fails due to low management, hidden cost, poor communication and business uncertainty [33]. Service level agreement (SLA) is an effective tool for managing outsourcing and to improve interorganizational relationships. A good contractual safeguard increase the trust between parties [33,34].

SLA used for service level agreement in outsourcing contract. It is formal written agreement between the client and vendor that are used to contract out the specific services at certain level [35]. Trust is an action through which one party assume that their counterpart will accomplish their requirement through some future actions[36]. Trust creating a confidence between the client and vendor in outsourcing relationship, whereas vendor try to meet the target performance and accomplishing specified goal in the SLA [37].

Dibbern et al, [17] stated that contract negotiation, association and arranging management based on the proper relationship to answer "How should it outsourced" or "How to do". The critical success factors for the successful outsourcing associated with vendor governance [38]. Contract is the primary tool whereas IS outsourcing relationships have been governed [38]. Proper contract and their efficient management is the key of success for managing long term outsourcing contract. There is lack of research on this area [39]. IT governance is the organizational capability, which is exercised by the executive management, in order to implement the IT strategies [40]. Performance management is the critical success factor and the SLA plays a key role for management of the vendor's behavior [23]. Alborz et al, [41] defined a technique for measuring the performance of success relationship. The different clauses about the outsourcing contracts used are: Service Level Agreements, Penalty-Reward-System, Pricing, Benchmarking, Change Requests, Renegotiation Option, Liability \& Insurance, dispute Resolution, Exit Management, Audit, confidentiality and IP rights [16, 39, 4245]. 
Offshore software development outsourcing contract from vendors' perspective: a systematic

The past research exercised on partnership factors but there is no focused on the attributes of partner relationships that enhance their quality. Goo et at, [46] extends the past research work and integrate the present views of contract. It is acknowledged that contracts and relational governance concern as a complement, where as the relationship commitment and trust are the key attributes in relational governance that effect the interorganizational performance. Formal control is a written contract, management-initiated is a mechanism that planed to guide towards objectives. However, the relational governance is unwritten contract, that is workerbased mechanisms to influence interorganizational behavior [46].

Outsourcing Contract Management can play an significant role for construction of relationship between both the parties, but also a successful completion of software outsourcing development [1]. Our previous work shows that in first decade (1990-99) the poor contract has 61\% frequency, which shows that it is the vast barrier for vendor in their selection for software outsourcing project, however this frequency shrank up to $39 \%$ in the second decade [1]. Contract management is the most critical success factor in outsourcing project [1]. To identify the critical success factors and critical barriers of the contract management, an approach of the Systematic Literature Review (SLR) [47] will be exercised. Kitchenham et al,[47] defined the three main phases of SLR that are Planning, Conducting, and Reporting the review. Our current work is actually the planning phase of the SLR, which has been discussed in this paper. Implementation of the protocol is in progress and the findings of SLR will be published in the near future accordingly.

\section{Systematic Literature Review Protocol}

This paper contribute to design the SLR protocol for Outsourcing Contract Management Model (OCMM) in offshore software outsourcing relationships from vendors' perspective by using the guideline of Kitchenham [47]. The SLR having three main phases of systematic review i.e. Planning, conducting and reporting the review [47]. In this paper we exercise the planning phase and it will produce the systematic review protocol that will generate the aim and procedure for the review. It is stated that the pre-defined protocol definition reduce the possibility of researcher bias [47]. While designing the protocol, we have studied various protocols for guidance [48-51].

SLR process is presented in Figure.3:

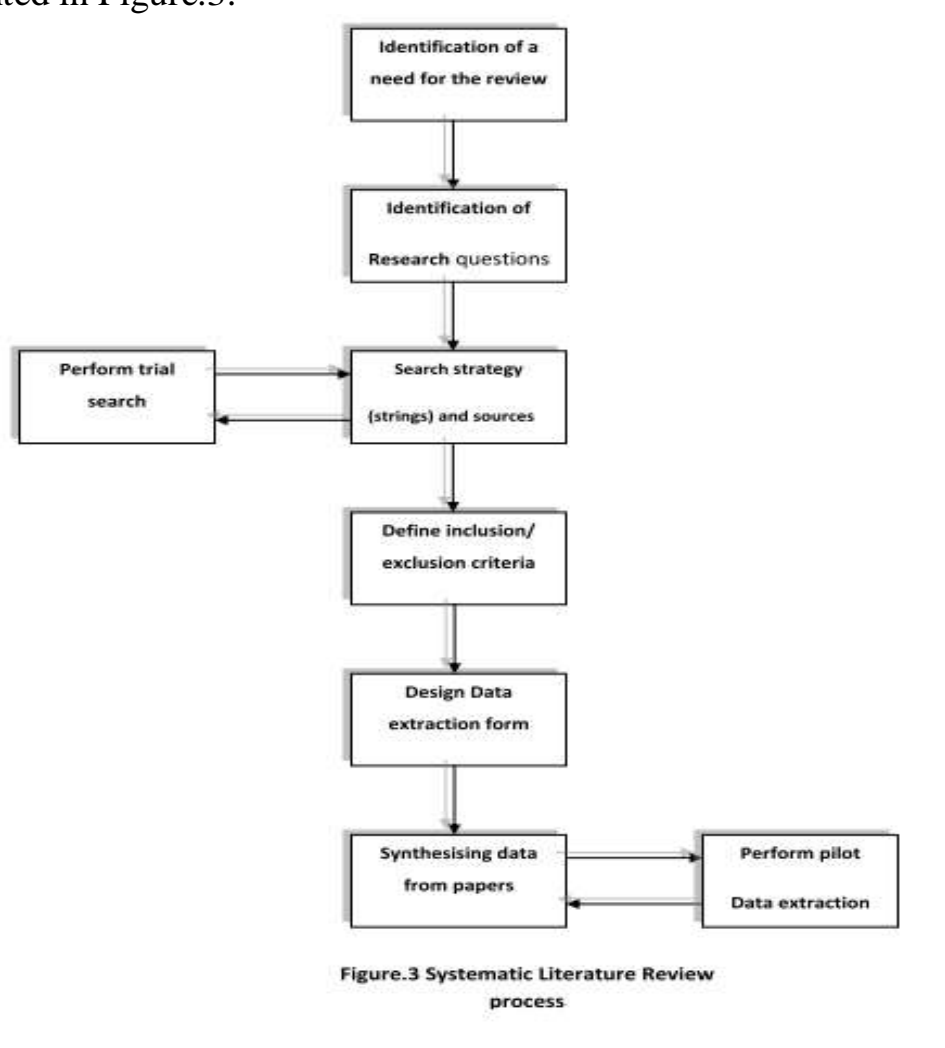

\section{Research Questions:}

RQ1. What are the factors to be considered by vendor organizations at various stages (pre- contract, duringcontract and post-contract) in order to design an effective offshore software development outsourcing contract? 
Offshore software development outsourcing contract from vendors' perspective: a systematic

RQ2. What are the barriers to be avoided by vendor organizations at various stages (pre- contract, duringcontract and post-contract) in order to design an effective offshore software development outsourcing contract?

RQ3. What are the real world practices, as identified in the literature, for successful outsourcing contract management?

RQ4. What are the real-world practices for management and execution of offshore software development outsourcing contract? ${ }^{1}$

\subsection{Constructing Search Term}

The following detail will assist us in designing a search term relevant to our research questions.

Population: Software outsourcing vendors and clients

Intervention: Success factors, barriers, characteristics

Outcomes of relevance: Efficient contract management, effective contract management model

Experimental Design: Empirical studies, systematic literature review, theoretical studies, experts' opinions, case studies.

An example of the Research Question containing the above details is given below:

RQ1.

[What factors/characteristics]......"INTERVENTION"

are important for

[Software Outsourcing vendor]. "POPULATION" in order to design an

[Effective outsourcing contract management]....."OUTCOMES OF RELEVANCE"

RQ2.

[What barriers/ problems] ..INTERVENTION"

to be avoided by

[Software outsourcing vendor]..."POPULATION"

in order to design an

[Effective outsourcing contract management]...'OUTCOMES OF RELEVANCE"

RQ3.

[What are the real world practices]........."INTERVENTION"

as identified in

[Software outsourcing literature]..."POPULATION"

for successful

[Outsourcing contract management]..”OUTCOMES OF RELEVANCE"

\subsection{Trial search:}

\section{Search strategies:}

A trial search was conducted using the following search string in ScienceDirect, IEEEXplore, SpringerLink and ACM digital library.

(("Outsourcing contracts" OR "software outsourcing" OR "IT outsourcing" OR "IS/IT outsourcing") AND ("contract management" OR "contract negotiation" OR "pre-contract" OR "post-contract" OR "during-contract" OR contracting) AND (factors OR characteristics OR features OR barriers OR risks OR problems OR "contractual issues") AND (vendors OR suppliers OR developers))

The papers retrieved through this search string will be used as a guide for the development and validation of the major search terms and the desired protocol.

\subsection{Identifying Search Terms characteristics}

The following search strategy is used for the construction of search terms/strings.

a) Use the Research Questions for the derivation of major terms, by identifying population, intervention and outcome;

b) For these major terms, find the alternative spellings and synonyms;

c) Verify the key words in any relevant paper;

d) Use of Boolean Operators for conjunction if the database allows, in such a way, to use 'OR' operator for the concatenation of alternative spellings and synonyms whereas 'AND' for the concatenation of major terms.

e) Integrate the search strategy into a summarize form; if required.

\section{Results for a)}

\footnotetext{
${ }^{1} \mathrm{RQ} 4$ will be executed in our future work through questionnaire survey.
} 
RQ1: offshore software outsourcing, vendor, factors, positive impact on client, vendor selection process, outsourcing contract, pre-contract, during-contract, post-contract

RQ2: offshore software outsourcing, barriers, negative impact on client, vendor selection process, establishing contract management, pre-contract, during-contract, post-contract

RQ3: Offshore software outsourcing, Real World, practices, solution, contract management

Results for $b$ )

(i) RQ1:

Software outsourcing: ("software outsourcing" OR "information systems outsourcing" OR "information technology outsourcing" OR "IS outsourcing" OR "IT outsourcing" OR "CBIS outsourcing" OR "computerbased information systems outsourcing" OR "software facility management" OR "software contracting-out")

Vendor(s): (vendor OR vendors OR service-provider OR dealer OR trader OR marketer OR seller OR developer)

Factors: (factors OR drivers OR motivators $\mathrm{OR}$ elements $\mathrm{OR}$ characteristics $\mathrm{OR}$ parameters) Outsourcing Contract: ("outsourcing contracts" OR "outsourcing agreement" OR "outsourcing marriage" OR "contract" OR "outsourcing relationship" OR "contractual coordination" OR "IT contract" OR "relational governance" OR "contracting" OR "contractual agreement" OR "co-ordination" OR "Relationship management")

Contract stages: ("contract level" OR "contract stages" OR "agreement level" OR "contracting levels" OR "post-contract" OR "pre-contract" OR "during contract")

(ii) RQ2:

Software outsourcing: ("software outsourcing" OR "information systems outsourcing" OR "information technology outsourcing" OR "IS outsourcing" OR "IT outsourcing" OR "CBIS outsourcing" OR "computerbased information systems outsourcing" OR "software facility management" OR "software contracting-out")

Barriers: (barriers OR barrier OR obstacles OR hurdles OR risks OR "risk analysis" OR "critical factors")

Vendor(s): (vendors OR vendor OR service-provider OR dealer OR trader OR marketer OR seller OR developer)

Outsourcing Contract: ("Outsourcing contracts" OR "outsourcing agreement" OR "outsourcing marriage" OR "contract" OR "outsourcing relationship" OR "contractual coordination" OR "IT contract" OR "relational governance" OR "contracting" OR "contractual agreement" OR "co-ordination" OR "Relationship management")

Contract stages: ("contract level" OR "contract stages" OR "agreement level" OR "contracting levels" OR "post-contract" OR "pre-contract" OR "during contract")

(iii) RQ3:

Outsourcing contract: ("Software outsourcing contract" OR "Outsourcing contract" OR "Outsourcing contract management")

Practice: (Solution OR "Best practice" OR practice OR "Lessons learned" OR "Process improvement" OR "Process enhancement" OR "Process innovation" OR SPI OR Advice)

\section{Result for c)}

IS/IT outsourcing, vendor selection criteria, motivators, risk analysis, outsourcing alliance, vendor screening, Offshore software outsourcing relationships, outsourcing agreement, relational governance, contractual coordination, contract management, contractual mechanism, contracted, partnership, outsourcing contract, software outsourcing vendor, contractual relationship, contract behavior, managing trust relationship, interorganizational relationship, contracted, outsourcing agreement, performance management, governance management, practice, solution, advice.

Result for d)

(i) RQ1:

(("Outsourcing contract" OR "software outsourcing" OR "information systems outsourcing" OR "information technology outsourcing" OR "IS outsourcing" OR "IT outsourcing" OR "CBIS outsourcing" OR "computerbased information systems outsourcing" OR "software facility management" OR "software contracting-out") AND (factors OR drivers OR motivators OR elements OR characteristics OR parameters) AND ("Outsourcing contracts" OR "outsourcing agreement" OR "outsourcing marriage" OR "contract" OR "outsourcing relationship" OR "contractual coordination" OR "IT contract" OR "relational governance" OR "contracting" OR "contractual agreement" OR "co-ordination" OR "Relationship management" OR "contract level" OR "contract stages" OR "agreement level" OR "contracting levels" OR "post-contract" OR "pre-contract" OR "during contract"))

(ii) RQ2: 
Offshore software development outsourcing contract from vendors' perspective: a systematic

(("Outsourcing contract" OR "software outsourcing" OR "information systems outsourcing" OR "information technology outsourcing" OR "IS outsourcing" OR "IT outsourcing" OR "CBIS outsourcing" OR "computerbased information systems outsourcing" OR "software facility management" OR "software contracting-out") AND (barriers OR barrier OR obstacles OR hurdles OR risks OR "risk analysis" OR "critical factors") AND ("Outsourcing contracts" OR "outsourcing agreement" OR "outsourcing marriage" OR "contract" OR "outsourcing relationship" OR "contractual coordination" OR "IT contract" OR "relational governance" OR "contracting" OR "contractual agreement" OR "co-ordination" OR "Relationship management" OR "contract level" OR "contract stages" OR "agreement level" OR "contracting levels" OR "post-contract" OR "precontract" OR "during contract"))

iii. RQ3:

(("Outsourcing contract management" OR "Software outsourcing contract management") AND (Solution OR "Best practice" OR practice OR "Lessons learned" OR "Process improvement" OR "Process enhancement" OR "Process innovation" OR SPI OR Advice))

\subsection{Search String Break-Up}

We will use the search strings RQ1,RQ2 and RQ3 defined in (d) as our search terms. Some of the databases/ libraries don't permit lengthy search strings, therefore the large search strings are split into small substrings and will search separately for each of substrings. Finally obtained results are summarized by removing the redundancy. It should be noted that while using IEEEXplore digital library, the prior mentioned search string will be used such that it should be put in large rectangular text-boxes not into small text box mentioned in advanced search for library.

The substring for the defined research question RQ1 and RQ2 are given below. Each search term in the research question is divided into sub term accordingly.

\section{Substrings for RQ1:}

Search String 1:

(("Outsourcing contract" OR "software outsourcing" OR "information systems outsourcing") AND (factors OR drivers OR motivators) AND ("Outsourcing contracts" OR "outsourcing agreement" OR "outsourcing marriage" OR "contract" OR "outsourcing relationship"))

Search String 2:

(("information technology outsourcing" OR "IS outsourcing" OR "IT outsourcing" OR "CBIS outsourcing" OR "computer-based information systems outsourcing") AND (elements OR characteristics OR parameters) AND ("contractual coordination" OR "IT contract" OR "relational governance" OR "contracting" OR "contractual agreement" OR "co-ordination"))

\section{Search String 3:}

(("Outsourcing contract" OR "software facility management" OR "software contracting-out") AND (factors OR drivers OR motivators) AND ("Relationship management" OR "contract level" OR "contract stages" OR "agreement level" OR "contracting levels" OR "post-contract" OR "pre-contract" OR "during contract"))

\section{Substrings for RQ2:}

\section{Search String 1:}

(("Outsourcing contract" OR "software outsourcing" OR "information systems outsourcing") AND (barriers OR barrier OR obstacles) AND ("Outsourcing contracts" OR "outsourcing agreement" OR "outsourcing marriage"))

\section{Search String 2:}

("“information technology outsourcing" OR "IS outsourcing" OR "IT outsourcing") AND (hurdles OR risks OR "risk analysis") AND ("contract" OR "outsourcing relationship" OR "contractual coordination"))

\section{Search String 3:}

(("Outsourcing contract" OR "CBIS outsourcing" OR "computer-based information systems outsourcing" OR "software facility management") AND (barriers OR barrier OR "critical factors") AND ("IT contract" OR "relational governance" OR "contracting"))

\section{Search String 7:}

(("Outsourcing contract" OR "software contracting-out") AND (barriers OR barrier OR "critical factors") AND ("contractual agreement" OR "co-ordination" OR "Relationship management" OR "contract level" OR "contract stages" OR "agreement level" OR "contracting levels" OR "post-contract" OR "pre-contract" OR "during contract"))

\subsection{Resources to be Searched}

- IEEE Xplore

- ACM Portal

(http://ieeexplore.ieee.org/Xplore/guesthome.jsp)

- ScienceDirect

- Cite Seer Digital Library

- $\quad$ SpringerLink (http://dl.acm.org/) (www.sciencedirect.com) (www.citeseer.ist.psu.edu) (www.springerlink.com) 
- Google Scholar (www.scholar.google.com)

Table.1 Detail of search result

\begin{tabular}{|c|c|c|c|c|c|c|c|}
\hline & & & earch results & n different & atabases & & \\
\hline & $\mathrm{ACM}$ & ScienceDirect & IEEEXplore & CiteSeerX & SpringerLink & GoogleScholar & Total \\
\hline RQ1 & 705 & $\begin{array}{c}1112 \\
\text { (1000 access) }\end{array}$ & 212 & $\begin{array}{c}1015 \\
(500 \\
\text { access })\end{array}$ & & & 3044 \\
\hline Str1 & & & & & 286 & 549 & 835 \\
\hline Str2 & & & & & 6 & 112 & 118 \\
\hline Str3 & & & & & 31 & 613 & 644 \\
\hline RQ2 & 578 & $\begin{array}{c}1022 \\
(1000 \text { access })\end{array}$ & 162 & $\begin{array}{c}877 \\
(500 \\
\text { access })\end{array}$ & & & 2639 \\
\hline Str4 & & & & & 47 & 807 & 854 \\
\hline Str5 & & & & & 427 & 701 & 1128 \\
\hline Str6 & & & & & 39 & 66 & 105 \\
\hline Str7 & & & & & 26 & 426 & 452 \\
\hline RQ3 & 08 & 03 & 105 & $\begin{array}{c}611 \\
(500 \\
\text { access })\end{array}$ & 3 & 68 & 798 \\
\hline Total & 1291 & 2137 & 479 & 2503 & 865 & 3342 & 10617 \\
\hline $\begin{array}{l}\text { Primary } \\
\text { Selection }\end{array}$ & 138 & 63 & 129 & 29 & 53 & 140 & 552 \\
\hline Duplication & 17 & 18 & 01 & 08 & 17 & 36 & 97 \\
\hline Balance PS & 121 & 45 & 128 & 21 & 36 & 104 & 455 \\
\hline
\end{tabular}

\subsection{Search Constraints and Validation}

Our searching for the related search in the different published paper doesn't have any date boundaries. Major search terms ("Outsourcing contract" OR "software outsourcing" OR "IS outsourcing") AND ("contract" OR "agreement" OR "Relationship" OR "software outsourcing contract”) AND ("Management" OR "Maintenance" OR "Performance" OR "governance") AND ("vendor" OR "selection criteria" OR "client" OR "factors" OR "barriers" OR "models")

\subsection{Search Documentation}

Documentation of the search will be maintained properly and the below data will be extracted: Database Name, Search Methodology, Search phase, Searching date, year exposed (All), No of publication found, Initial selection decision, Final selection decision.

Table 2: documentation of trial search string

\begin{tabular}{|c|c|c|c|c|c|c|c|}
\hline Name of DB & Search Strategy & $\begin{array}{l}\text { Search } \\
\text { string } \\
\text { no }\end{array}$ & $\begin{array}{l}\text { Date } \\
\text { of } \\
\text { Search }\end{array}$ & $\begin{array}{l}\text { Year } \\
\text { covered } \\
\text { by } \\
\text { search }\end{array}$ & $\begin{array}{l}\text { No. of } \\
\text { publicat- } \\
\text { ion found }\end{array}$ & $\begin{array}{l}\text { Initial } \\
\text { selection } \\
\text { decision }\end{array}$ & $\begin{array}{l}\text { Final } \\
\text { selecti- } \\
\text { on } \\
\text { decisio } \\
\text { n }\end{array}$ \\
\hline IEEEXplore & \multirow{4}{*}{$\begin{array}{l}\text { (("Outsourcing contracts" } \\
\text { OR "software outsourcing" } \\
\text { OR "IT outsourcing" OR } \\
\text { "IS/IT outsourcing") AND } \\
\text { ( "contract management" } \\
\text { OR "contract negotiation" } \\
\text { OR "pre-contract" OR } \\
\text { "post-contract" } \\
\text { "during-contract" OR } \\
\text { contracting) AND (factors }\end{array}$} & \multirow{4}{*}{$\begin{array}{l}\text { Trail } \\
\text { Search }\end{array}$} & \multirow{4}{*}{$\begin{array}{l}13 / 4 / .2 \\
012\end{array}$} & \multirow[t]{4}{*}{ All } & 55 & & \\
\hline ACM & & & & & 219 & & \\
\hline ScienceDirect & & & & & $\begin{array}{l}(400+832) \\
=1232\end{array}$ & & \\
\hline Sprigerlink & & & & & 275 & & \\
\hline
\end{tabular}


Offshore software development outsourcing contract from vendors' perspective: a systematic

OR characteristics OR

features OR barriers OR

risks OR problems OR

"contractual issues") AND

(vendors OR suppliers OR

developers))

5.7 Search Result Management

The primary source references will be stored electronically in a directory on the University of Malakand Server. The results will be managed as shown in table 3.

Table 3: Search result management

\begin{tabular}{llll}
\hline $\begin{array}{l}\text { S.N } \\
\mathbf{O}\end{array}$ & Tracing NO. & Database & Paper Title \\
\hline $\mathbf{1}$ & IEEE-2 & IEEEXplore & $\begin{array}{l}\text { Assessing the Business Value of Using } \\
\text { Information Systems: Case of UTi Egypt }\end{array}$ \\
$\mathbf{2}$ & SP1-249 & SpringerLink & $\begin{array}{l}\text { A US Client's learning from outsourcing IT } \\
\text { work offshore } \\
\text { An evaluation of simulation to support } \\
\text { contract costing }\end{array}$ \\
\hline
\end{tabular}

VI. Publication Selection

This section of the paper define the criteria for inclusion, exclusion and the selection primary sources, so only those publications will be in count which are relevant to the research questions. The focus of this paper will be on the offshore outsourcing contract and nearshore outsourcing or onshore outsourcing paper will not be considered.

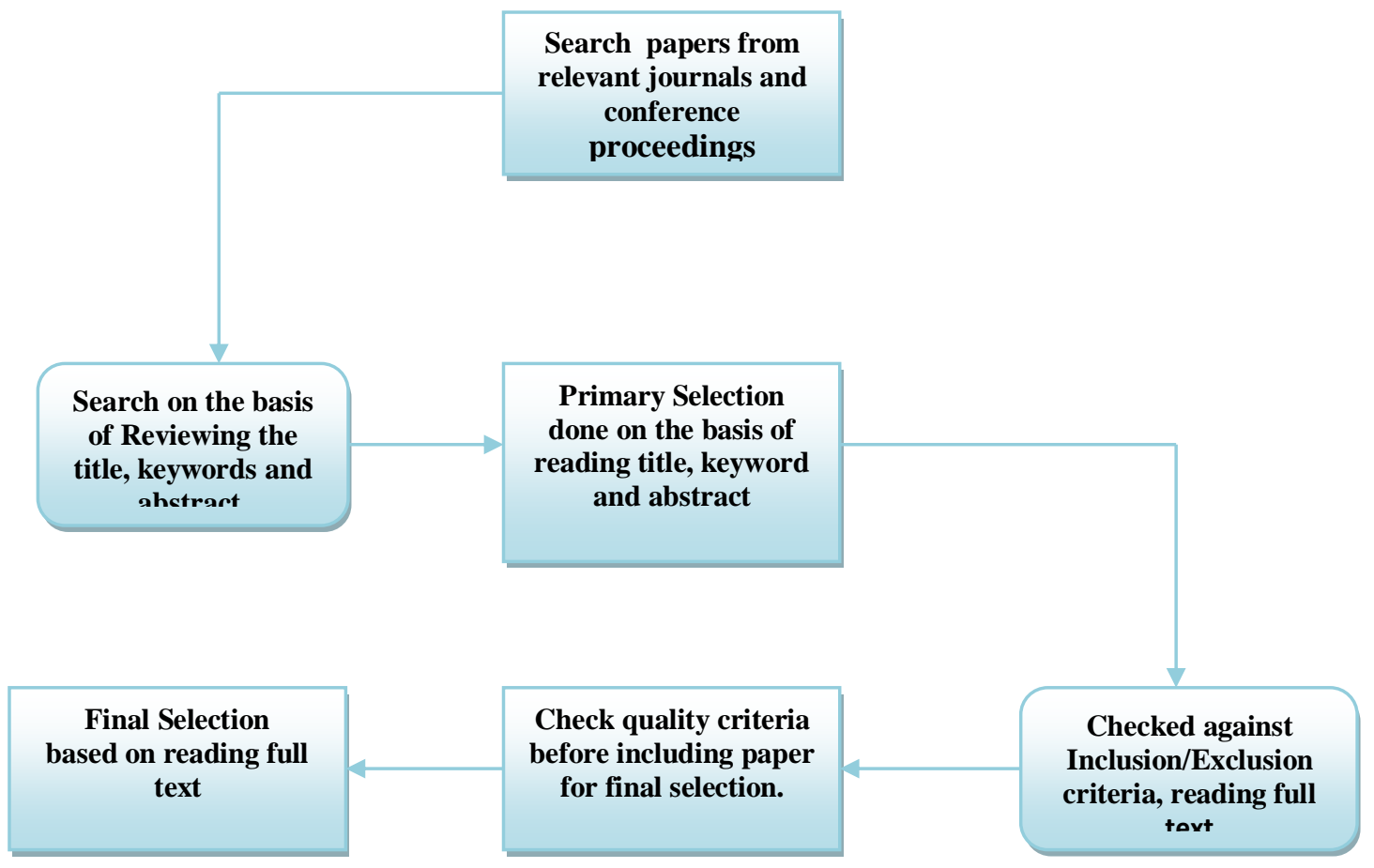

\section{Figure.2 Publication selection}

\subsection{Inclusion Criteria}

This criteria used for the purpose to define which part of literature (papers, technical reports, or 'grey literature') found by the search term will be used for data extraction. Our consideration will be only for offshore outsourcing and paper written in English. The criteria are listed below:

- Studies that describe vendor's capability for software outsourcing contract.

- Studies that define the critical success factors in the contract management process of software outsourcing vendor.

- Studies that describe the critical barriers in the contract management process of software outsourcing vendor. 
- Studies that describe the relationship between software outsourcer and vendor.

- Studies that describe criteria for a successful software outsourcing contract.

- Studies that describe motivation for software outsourcing contract management.

- Studies that describe issues in software outsourcing contract management.

- Studies that describe effectiveness in the outsourcing contract management.

- Studies that describe contract management in the outsourcing.

- Studies that describe vendor role for effectiveness of the contract.

- Include papers written in English language.

- Include paper whose title is related to outsourcing contract management.

- Include paper that contain keywords that match with those defined in the search strings.

\subsection{Exclusion Criteria}

This criteria used to exclude those pieces of the literature (papers, technical reports, or 'grey literature') found by the search term. The criteria are listed below:

- Studies that have not matching to the research questions.

- Studies which is not about the client or vendor;

- Studies that don't describe factors or barriers of the contract management of the software outsourcing vendor.

- Studies which is not relevant to offshore outsourcing.

- Studies which not satisfied the outsourcing contract management

- Studies which based on the expert opinions.

- Exclude all duplicate papers.

\subsection{Selecting primary Sources}

Initial selection of primary sources will be performed by reviewing the title, keywords and abstract of the papers. The purpose of this finding is to exclude the result irrelevant to the problem.

This source of study conducted to check against the inclusion/exclusion criteria through complete review of the articles. The secondary reviewer is requested to review the source, in case of any uncertainty regarding the inclusion or exclusion of a particular primary study. The record is properly maintained of the primary source regarding the inclusion/exclusion criteria. The primary source data is desirable whether to include or not in the final review.

\section{Publication Quality Assessment}

The measurement of the quality is performed after final selection of publications. It is quality is assessed in parallel at the time of data extraction. The quality preformed on the bases of the following questions:

- Is it clear how the vendor screening was performed?

- Is it clear how the critical success factors (CSFs) of the contract management for software outsourcing vendor were identified in the outsourcing business?

- Is it clear how the critical barriers (CBs) of the contract management for the software outsourcing vendor in the outsourcing business?

- Is it clear that no expert opinion taken?

The above mentioned factors will be marked as 'YES' or 'NO' or 'NA'.

My supervisor (secondary reviewer) will score a small subset for validation.

\subsection{Primary Study Data}

\section{Data Extraction Strategy}

Data collection from the publication is performed through this study, which is focused on satisfying the research questions for the review. The data which will be extracted from each of the publication are as below.

- Publication details (Title, Authors, Journal/Conference title, etc)

- Data that address the research questions.

The following data will be extracted that address the research questions:

RQ1:

- Background information, Critical Success Factors (CSFs): factors that have positive impact on software RQ2: outsourcing vendor for the proper development of software outsourcing contract management. 
Offshore software development outsourcing contract from vendors' perspective: a systematic

- Background information, Critical Barrier Factors (CBs): factors that have negative impact on software outsourcing vendor for the proper development of software outsourcing contract management. RQ3:

- Background information, Practices: practice or solution or advice that will be identified in the literature for the proper development of software outsourcing contract management.

The data to be captured in the data extraction form is presented as follow:

\section{Table 4 Data to be extracted}

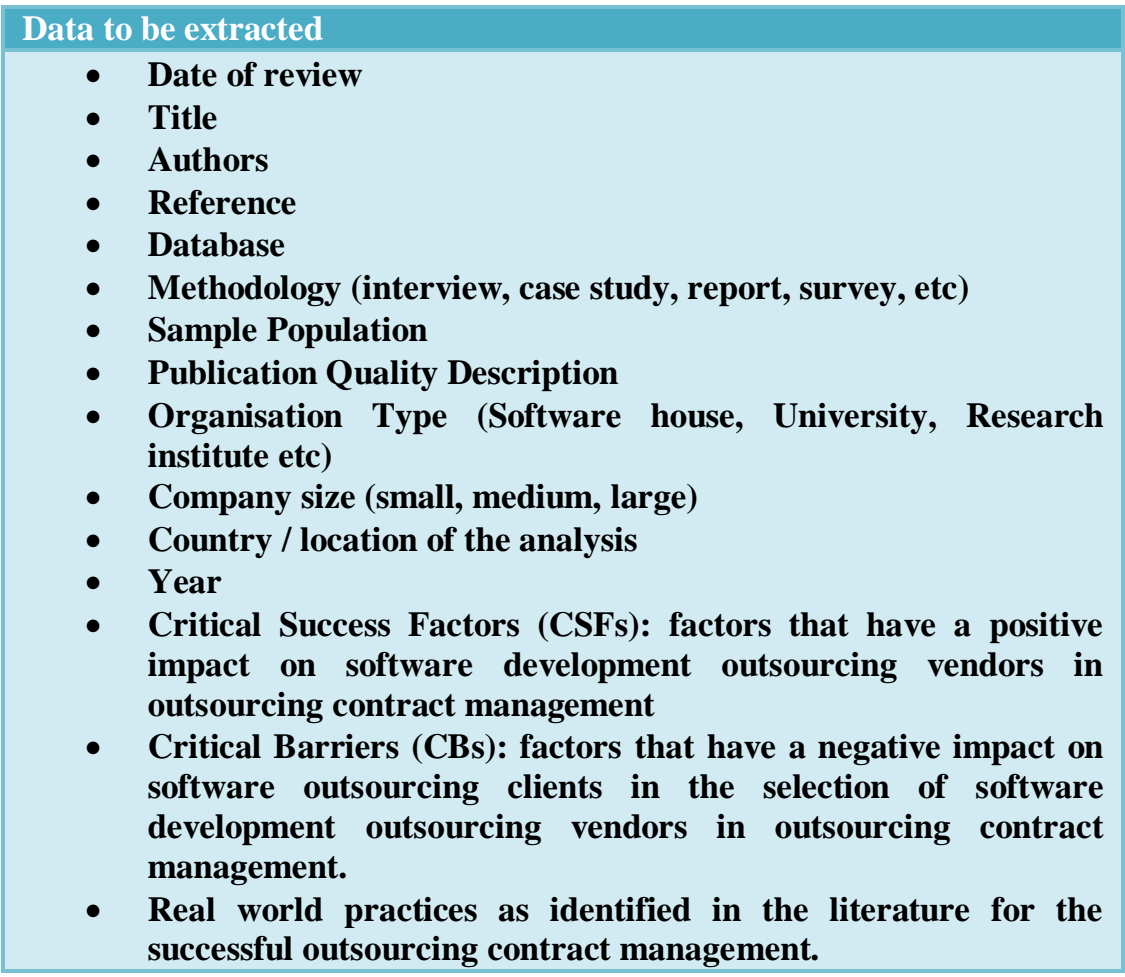

\subsection{Data Extraction Process}

The primary review will be commenced by a single researcher, who will be responsible for data extraction. In case of an issue regarding the data extraction the secondary reviewer will give the guidance.

The primary reviewer is responsible for inter-rater reliability test after the data extraction process. The secondary reviewer will select randomly from the already chosen publication of the primary reviewer. The secondary reviewer will extract independently from the random selected publication and the result will compare with the finding of the primary reviewer.

\subsection{Data Storage}

The summarize data for each publication will be kept as SPSS document and will be stored on local drive at University of Malakand.

\section{Data Synthesis}

The data will be synthesized by creating one summary table having the columns (S.No, Outsourcing contract challenges, Frequency, Percentages) showing the list of all the Outsourcing contract challenges along with their frequencies and percentages.

\section{Validation of the Review Protocol}

a. First reviewer comments:

The protocol presented to the SERG_UOM group of software engineering University of Malakand on 12June-2012 and they have approved and validate it.

b. Second reviewer comments:

The protocol is reviewed by the SERG_UOM group member Muhammad Ilyas and the suggested changes was made in the protocol accordingly.

c. Third reviewer comments:

The supervisor has reviewed the OCMM Protocol and enhance the protocol. 


\section{Divergences}

In case of any variance from the protocol, which may occur during the study, we will record any change in a new Appendix to this document.

\section{LIMITATION}

- Some of the digital libraries do not give data e.g CiteSeerX digital library show only 500 results out of 1000 and ScienceDirect shows only 1000 result out of $1000+$.

- To find the efficient result from google scholar the integrated rule 'e' are used.

- To find the real world practices in the existing literature a new research question third (RQ3) included.

- The RQ4 will be used to find real world practices using empirical (questionnaire survey) will be conducted

\section{Acknowledgment}

We are thankful to University of Science \& Technology Bannu and University of Malakand for their contribution in our research activities. We are thankful to Software Engineering Research Group University of Malakand (SERG_UOM), the reviewer and my fellows for their assistance in the review process.

\section{Reference:}

[1]. Khan, S.U., Software Outsourcing Vendors' Readiness Model ,PhD thesis, in School of Computing and Maths. 2011, Keele Graduate School, UK. p. 381.

[2]. Lago, P., H. Muccini, and M. Ali-Babar. Developing a Course on Designing Software in Globally Distributed Teams. in IEEE International Conference on Global Software Engineering, ICGSE08. 2008.

[3]. Ali-Babar, M., J. Verner, and P. Nguyen, Establishing and maintaining trust in software outsourcing relationships: An empirical investigation. The Journal of Systems and Software, 2007. 80(9): p. 1438-1449.

[4]. Palvia, P.C., A dialectic view of information systems outsourcing - pros and cons. Information and Management, 1995. 29(5): p. $265-275$.

[5]. Hongxun, J., et al. Research on IT outsourcing based on IT systems management. in ACM International Conference Proceeding Series, Vol. 156. 2006.

[6]. United-Nations, World Investment Report. The shift towards services, New York and Geneva. 2004.

[7]. Lacity, M.C. and L.P. Willcocks, Global Information Technology Outsourcing. Wiley, Chichester, 2001.

[8]. McCarthy, J., 3.3 Million U.S. Services Jobs to Go Offshore. Forrester Research, 2002.

[9]. Palvia, S.C.J., Global Outsourcing of IT and IT Enabled Services: Impact on US and Global Economy. Journal of Information Technology Case and Applications, 2003. 5(3): p. 1-8.

[10]. Oza, N.V., Hall, Tracy, Rainer, Austen and Grey, Susan Grey., Trust in software outsourcing relationships: An empirical investigation of Indian software companies,. Information \& Software Technology, 2006. 48(5): p. 345-354.

[11]. O2pi.com, Outsourcing Survey Report, 2008 (www.o2pi.com). 2008.

[12]. Smite, D., et al., Empirical evidence in global software engineering: a systematic review. Empirical Software Engineering, 2010. 15(1): p. 91-118.

[13]. Lee, M.K.O., IT Outsourcing Contract: Practical Issues for Management. 2003.

[14]. Lacity, M. and L. Willcocks, IT Outsourcing: Maximize flexibility and control. Harward Business Review, 1995.

[15]. Gong, H.T., M. Alborz, S., Managing the Outsourcing Marriage to Achieve Success. IEEE, 2007.

[16]. Harris, A., L.C. Giunipero, and G.T.M. Hult, Impact of Organizational and Contract Flexibility on Outsourcing Contracts. Industrial Marketing Management, 1998. 27: p. 373-384.

[17]. Dibbern, J., et al., Information System Outsourcing: A Survey and Analysis of the Literature. The DATA BASE for Advances in Information Systems -Fall, 2004. 35.

[18]. Lacity, M. and L. Willcocks, An empirical investigation of Information Technology sourcing practices: Lesson from experience. Mis Quarterly,, 1998.

[19]. Streitfeld, D., Indian City Rides Tech Euphoria, in Los Angeles Times. 2004: Los Angeles. p. 16-17.

[20]. Anonymous., The Place to Be. The Econonist, 2004: p. 10-12.

[21]. Fitzgerald, M., At Risk: Offshore. CIO Focus: Offshore Outsourcing Focus Guide, 2004: p. 1-73.

[22]. Kern, T. and L. Willcocks, The Relationship Advantage: Information Technology, Sourcing and Management. Oxford University press, 2001.

[23]. Kern, T. The Gestalt of an Information Technology Outsourcing Relationship: An Exploratory Analysis. in International Conference on Information Systems. 1997. Atlanta, Georgia.

[24]. DiRomualdo, A. and V. Gurbaxani, Strategic Intent for IT Outsourcing. Sloan Management Review, 2004. 39: p. 67-80.

[25]. Huai, J. Develop IT Outsourcing Contract Based on QFD. in Management and Service Science, 2009. MASS '09. 2009. Sch. of Econ. \& Manage., East China Jiaotong Univ., Nanchang, China.

[26]. Barthelemy, J., The Hard and Soft Sides of IT Outsourcing Management. European Management Journal, 2003. 21(5): p. 539548 .

[27]. A. Parkhe, Strategic Alliances Structuring a Game Theoretic and Transaction Cost Examination of Interfirm cooperation. Academy of Management, 1993. 36: p. 794-829.

[28]. Kern, T., L. Willcocks., and E.V. Heck, The Winner's Curse in IT Outsourcing: Strategies for avoiding Relational Trauma. California Management Review, 2002. 44: p. 17-69.

[29]. Bouman, J., J., M. Trienekens, J, J., and M. Van der Zwan. Specification of service level agreements, clarifying concepts on the basis of practical research. in International Workshop Software Technology and Engineering Practice. 1999. Los Alamitos: IEEE.

[30]. Trienekens, M., J, J., J. Bouman, J., and M. Van der Zwan, Specification of Service level Agreement: Problems, Principles and Practices. Software Quality Journal, 2004. 12: p. 43-57.

[31]. Keizer, G., Gantner Says Half of Outsourcing Projects Doomed to Failure. www.techweb.com/wire/showArticle.jhtml?articleID=26800868, 2003.

[32]. Deloitte Consulting, Calling a Change in the Outsourcing market: The Reality for the World's Largest Organizations, Deloitte \& Touche, . White paper, 2005. 
Offshore software development outsourcing contract from vendors' perspective: a systematic

[33]. Mayer, K.J. and N.S. Argyres, Learning to Contract : Evidence from the Personal Computer Industry. Organization Science, 2004. 15: p. 394-410.

[34]. $\quad$ Argyres, N. and K.J. Mayer, Contract Design as Firm Capability: An Integration of Learning and Transaction Cost Perspectives. Academy of Management, 2007. 32: p. 1060-77.

[35]. Singleton., J.P., E.R. McLean, and E.N. Altman, Measuring Information Systems Performance: Experience with the Management by Results System at Security Pacific Bank. Mis Quarterly, 1988. 12: p. 325-337.

[36]. A.Zaheer and N. Venkatraman, Relational Governance as an Interorganizational Strategy: An Empirical Test of the Role of Trust in Economic Exchange. Strategic Management, 1995. 16(5): p. 373-92.

[37]. T.Kern and L. Willcocks, Exploring Relationships in Information Technology Outsourcing: The Interaction Approach. European Journal of Information Systems, 2002. 11(1): p. 3-19.

[38]. Clark, T.D. and R.W. Zmud, The Outsourcing of Information services: Transforming the Nature of Business in the Information Industry. 1997, Working paper, Florida State University, Tallahassee.

[39]. Aubert, B., et al. Characteristics of IT Outsourcing Contracts. in Proceedings of the 36th Hawaii International Conference on System Sciences. 2003.

[40]. Van Grembergen, W. IT Governance and its Mechanisms- Introduction to Minitrack. in 39th Hawaii International Conference on System Sciences HICSS. 2006.

[41]. Alborz, S., P.B. Seddon, and R. Scheepers. A Model for Studying IT Outsourcing Relationships. in 7th Pacific Asia Conference on Information Systems PACIS. 2003. Adlaide, Australia.

[42]. Aubert, B., et al. Managing the risks of IT outsourcing. in Proceedings of the 32nd Annual Hawaii International Conference on System Sciences, 1999. HICSS-32. 1999. Maui, HI.

[43]. Kern, T. and L. Willcocks, Exploring information technology outsourcing relationships: theory and practice. Journal of Strategic Information Systems, 2000. 9(4): p. 321-350.

[44]. Lee, M., K, O., IT Outsourcing Contracts: Practical Issues for Management. Industrial Marketing Management \& Data Systems, 1996. 96:1: p. 15-20.

[45]. McFarlan, F., W. and R. Nolan, L., How to manage an IT Outsourcing Alliance. Sloan Management Review, 1995: p. 9-23.

[46]. Goo, J. and K. Nam. Contract as Source of Trust - Commitment in Successful IT Outsourcing Relationship: An Empirical Study. in 40th Hawaii International conference on System Sciences. 2007: IEEE.

[47]. Kitchenham, B. and C. Charters, Guidelines for performing Systematic Literature Reviews in Software Engineering, Keele University and Durham University Joint Report. 2007.

[48]. Alam, A.U. and S.U. Khan. Knowledge Sharing Management in Offshore Software Development Outsourcing Relationships from Vendors' Perspective: A Systematic Literature Review Protocol. in 5th Malaysian Conference in Software Engineering (MYSEC). 2011. Malaysia: IEEE.

[49]. $\quad$ Azeem, M.I. and S.U. Khan. Intercultural Challenges in Offshore Software Development Outsourcing Relationships: A Systematic Literature Review Protocol. in IEEE The 5th MALAYSIAN SOFTWARE ENGINEERING CONFERENCE, “MYSEC2011", 13 - 14 December 2011,THE PUTERI PACIFIC, JOHOR, Malaysia. 2011.

[50]. Khan, S.U. and M. Niazi, Systematic Literature Review Protocol for Software Outsourcing Vendors Readiness Model (SOVRM), Technical Report: TR/08-01, ISSN: 1353-7776, School of Computing and Maths, Keele University, UK. 2008.

[51]. Khan, S.U., M. Niazi, and N. Ikram, Systematic Literature Review Protocol for Software Outsourcing Relationships Trust (SORT). 2009, School of Computing \& Maths, Keele University, UK. 